\title{
CORRIGENDUM
}

\section{Effect of previous nutrition on body composition and maintenance energy costs of growing lambs}

\author{
By C. L. FERRELL, L. J. KOONG AND J. A. NIENABER
}

Vol. 56 (1986), no. 3

Page 601, Table 5, subheading

For

(Model is $\log$ (organ weight) $=b_{0}+b_{1} \times(\log E B W)+b_{2} \times A D G \times(\log E B W)$ or, if transformed, organ

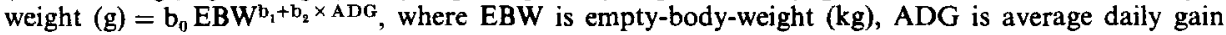
$(\mathrm{g} / \mathrm{d})$ and $\mathrm{b}_{0}, \mathrm{~b}_{1}$ and $\mathrm{b}_{2}$ are constants. Thirty-six observations are included in each regression)

Read

(Model is $\log _{e}$ (organ weight) $=b_{0}+b_{1} \times\left(\log _{e} E B W\right)+b_{2} \times A D G \times\left(\log _{e} E B W\right)$ which is the result of the transformation of the equation organ weight $(g)=b_{0}^{\prime} E B W^{b_{1}+b_{2} \times A D G}$, where $b_{0}^{\prime}=e^{b_{0}}$, EBW is empty body-weight $(\mathrm{kg})$, ADG is average daily gain $(\mathrm{kg} / \mathrm{d})$ and $b_{0}, b_{1}$ and $b_{2}$ are regression coefficients. Thirtysix observations are included in each regression) 